\title{
Activity-related dyspnea in chronic obstructive pulmonary disease: physical and psychological consequences, unmet needs, and future directions
}

This article was published in the following Dove Press journal: International Journal of Chronic Obstructive Pulmonary Disease

\author{
Nicola A Hanania' \\ Denis E O'Donnell ${ }^{2}$ \\ 'Department of Medicine, Section of \\ Pulmonary and Critical Care, Baylor \\ College of Medicine, Houston, TX, USA; \\ ${ }^{2}$ Division of Respirology, Department of \\ Medicine, Queen's University, Kingston, \\ Ontario, Canada
}

\begin{abstract}
Dyspnea is a distressing, debilitating, and near-ubiquitous symptom affecting patients with COPD. In addition to the functional consequences of dyspnea, which include activity limitation and reduced exercise tolerance, it is important to consider its psychological impact on patients with COPD, such as onset of depression or anxiety. Moreover, the anticipation of dyspnea itself can have a significant effect on patients' emotions and behavior, with patients frequently self-limiting physical activity to avoid what has become the hallmark symptom of COPD. Dyspnea is, therefore, a key target for COPD treatments Pharmacologic treatments can optimize respiratory mechanics, provide symptom relief, and reduce patients' increased inspiratory neural drive to breathe. However, it is important to acknowledge the value of non-pharmacologic interventions, such as pulmonary rehabilitation and patient self-management education, which have proven to be invaluable tools for targeting the affective components of dyspnea. Furthermore, it is important to encourage maintenance of physical activity to optimize long-term patient outcomes. Here, we review the physiological and psychological consequences of activity-related dyspnea in COPD, assess the efficacy of modern management strategies in improving this common respiratory symptom, and discuss key unmet clinical and research needs that warrant further immediate attention.
\end{abstract}

Keywords: dyspnea, chronic obstructive pulmonary disease, psychology, physiology, management

\section{Overview of dyspnea in COPD}

Dyspnea is defined by the American Thoracic Society as "a subjective experience of breathing discomfort that consists of qualitatively distinct sensations that vary in intensity". It is a distressing and debilitating symptom for patients with COPD. ${ }^{1}$ Activity-related dyspnea and exercise intolerance are key features of COPD and ultimately lead to reduced habitual physical activity, which can have a significant negative impact on patient quality of life. ${ }^{2}$

Dyspnea is highly prevalent in COPD. According to data from the Clinical Practice Research Datalink, $82 \%$ of patients with COPD had dyspnea of any grade, as assessed by the Medical Research Council (MRC) breathlessness scale (1-5), of whom $46 \%$ had moderate-to-severe dyspnea $(\mathrm{MRC} \geq 3) .^{3}$ Moderate-to-severe dyspnea was also observed in $32 \%$ of patients with mild airflow obstruction, indicating that dyspnea is not limited to patients with more severe COPD. ${ }^{3}$ Increased dyspnea intensity has been associated with older age ( $\geq 70$ years), increasing severity of airflow limitation, female
Correspondence: Nicola A Hanania Department of Medicine, Section of Pulmonary and Critical Care, Baylor College of Medicine, I504 Taub Loop, Houston, TX 77030, USA

Email hanania@bcm.edu 
gender, obesity (body mass index $\geq 30 \mathrm{~kg} / \mathrm{m}^{2}$ ), history of moderate-to-severe COPD exacerbations, and frequent visits to the family physician for COPD. ${ }^{3}$ COPD-related dyspnea has also been associated with comorbid psychological symptoms, such as depression and anxiety. ${ }^{4}$

The mechanisms of dyspnea and the reduction of exercise tolerance are multifactorial, encompassing physiological, psychological, and emotional factors. ${ }^{1}$ Here, we review our current understanding of the neurophysiology of dyspnea, its psychological underpinnings, and its link with long-term patient-related outcomes, along with key considerations and unmet needs in the management of this highly prevalent symptom of COPD.

\section{Current understanding of mechanisms of dyspnea}

Understanding the underlying mechanisms of dyspnea is essential for formulating a rational management plan. In chronic lung diseases, dyspnea is first reported during physical activity and generally reflects an increased neural drive to the respiratory muscles that are overburdened by increased intrinsic mechanical loading (Figure 1). Dyspnea is typically assessed using three main domains: sensoryperceptual experience (ie how breathing feels), affective distress (ie how distressing breathing feels), and symptom/ disease impact (ie how dyspnea affects functional ability, employment, quality of life, or health status). ${ }^{1}$

After exercise, increased effort/work and heavier breathing are reported in both healthy individuals and those with COPD, reflecting the increased motor command output and contractile muscle effort. In COPD, additional and dominant qualitative descriptors are reported, including sensations that allude to inspiratory difficulty and unsatisfied inspiration ("can't get enough air in"). This is believed to reflect the widened disparity during exercise between increased inspiratory neural drive and the blunted response of the respiratory system (neuromechanical dissociation). ${ }^{5-9}$

\section{Pathophysiology of dyspnea in COPD}

Integrated efferent inputs from brainstem chemical control centers and cortical motor centers contribute to the increased neural drive observed during dyspnea. These

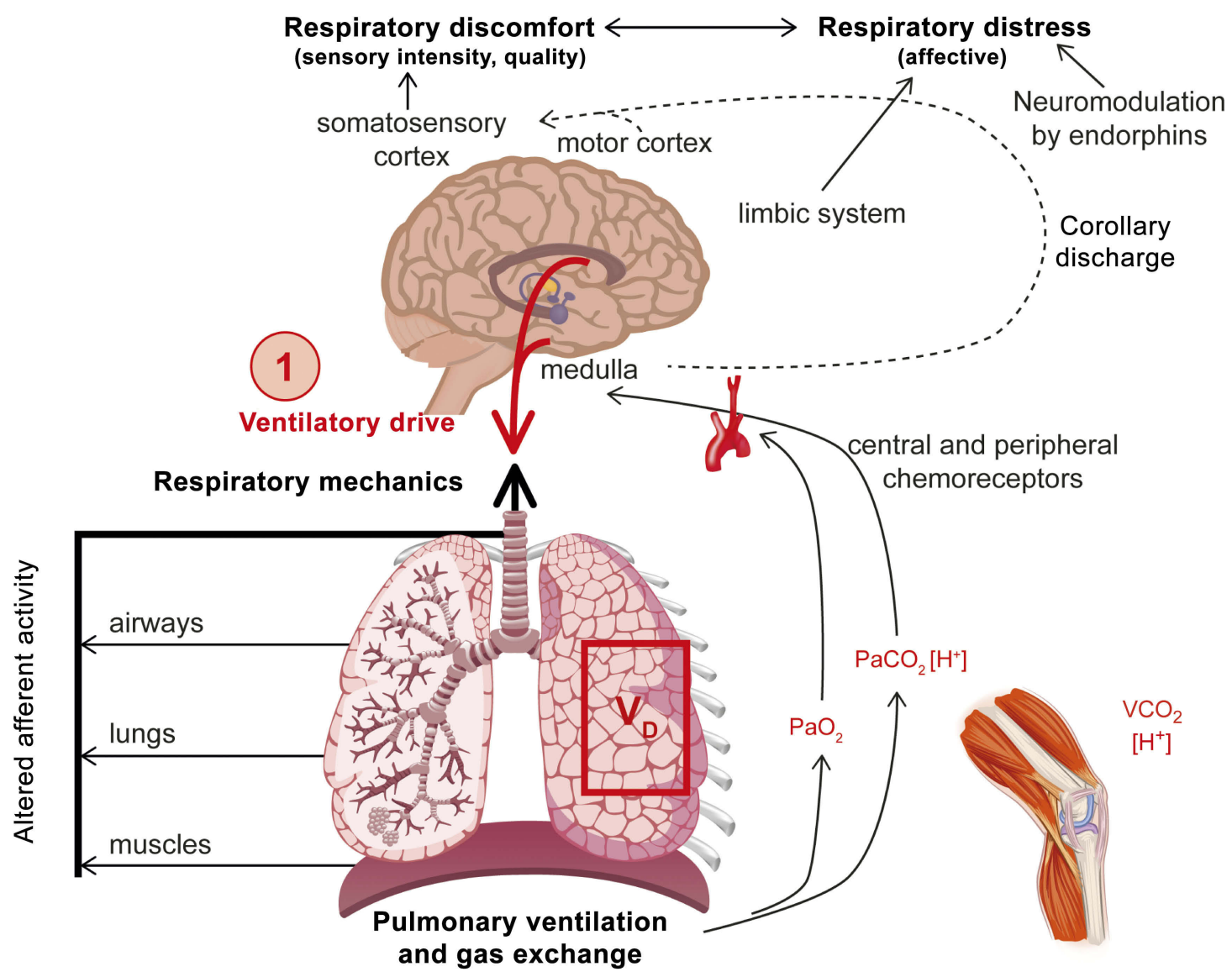

Figure I Inter-relationships of dyspnea.

Note: Reprinted from Chest, 147, Mahler DA and O'Donnell DE, Recent advances in dyspnea, 232-24I, Copyright (2015), with permission from Elsevier. ${ }^{16}$ Abbreviations: $\mathrm{PaCO}_{2}$, partial pressure of carbon dioxide; $\mathrm{PaO}_{2}$, partial pressure of oxygen; $\mathrm{VCO}_{2}$, volume of carbon dioxide. 
control centers regulate arterial blood gases and acid-base balance, and an abundance of mechanoreceptors in the lungs, airways, respiratory muscles, and chest wall provide precise afferent sensory information about dynamic tidal respiration on a breath-by-breath basis. ${ }^{10}$ The elevated efferent traffic from the brainstem and cortical motor centers is relayed directly to the somatosensory cortex (central corollary discharge) in which it is consciously perceived. ${ }^{10}$ Although inspiratory effort increases during exercise in a healthy individual, ${ }^{11}$ the motor output and central corollary discharge is perfectly coordinated with the muscle/ mechanical response of the respiratory system, enabling harmonious neuromechanical coupling. Healthy individuals are aware that their breathing requires more effort, but this is expected during high-intensity exercise and quickly recovers with rest, meaning that affective distress is not perceived. In COPD, the mismatch between increased medullary and cortical respiratory motor output and altered peripheral mechanoreceptor afferent feedback gives rise to neuromechanical dissociation and the associated perception of unsatisfied inspiration. ${ }^{8,12}$ In addition, the perception of increasing respiratory discomfort beyond a certain threshold (which varies among individuals) often creates an emotive or fear response, resulting in overactivation of the limbic, paralimbic, and sympathetic nervous systems. ${ }^{13}$

The link between the neurobiological mechanisms and the pathophysiology of COPD is complex and multifactorial. Fundamentally, increased fractional inspiratory neural drive to the diaphragm during exercise occurs mainly as a result of chemical perturbations caused by high physiological dead space in the lungs; in advanced COPD, physiological dead space is elevated due to a ventilation/ perfusion mismatch. Thus, in various lung regions, blood perfusion is diminished relative to ventilation and efficient gas exchange is compromised: carbon dioxide accumulates and oxygen decreases. The increased partial pressure of arterial carbon dioxide is readily sensed by chemoreceptors, which stimulate increased inspiratory neural drive and ventilation. This successfully mitigates hypoxemia, but at the expense of increasing breathing difficulty. ${ }^{14,15}$ Simultaneously, the mechanical response of the respiratory system is blunted because of the effects of resting, and dynamic lung hyperinflation and reduced inspiratory capacity (IC), which restricts tidal volume expansion and limits the functional ability of the inspiratory muscles. ${ }^{6,16,17}$ Under these conditions, dyspnea quickly escalates to intolerable levels during exercise, when tidal volume expansion plateaus (critical mechanical limitation) in the face of efferent inspiratory neural drive reaching near-maximal values. $^{18,19}$

Because this review focuses primarily on the neurophysiology of dyspnea, the cardio-circulatory dysfunction associated with limitation of exercise capacity in COPD has not been discussed. It remains unclear whether the increased drive to breathe in COPD, reflected in a high ratio of ventilation to $\mathrm{CO}_{2}$ output, represents a long-term adjustment of respiratory control centers and increased central chemosensitivity (ie altered arterial $\mathrm{CO}_{2}$ setpoint). In mild COPD, the strongest association with high minute ventilation/carbon dioxide production is high physiological dead space. ${ }^{20}$ Stickland et al found no association between central chemoreceptor activity/sensitivity and the ventilatory response to exercise in COPD. ${ }^{20}$

\section{Neurophysiological mechanisms of dyspnea}

Lung volume parameters, such as IC, rather than the spirometric measurements used in COPD diagnosis, provide more consistent correlates for dyspnea symptoms. ${ }^{21,22}$ During relaxed tidal breathing in healthy patients, end-expiratory lung volume (EELV), equivalent to the relaxation volume of the respiratory system after a quiet exhalation, is determined by the elastic properties of the lungs and chest wall. ${ }^{23}$ In patients with COPD, resting EELV is higher than in healthy individuals, reflecting the altered elastic properties of the lungs in patients with COPD. Additionally, the presence of expiratory flow limitation during resting breathing means that lung emptying is strongly influenced by the prevailing breathing pattern: if expiratory time is shortened, lung emptying is incomplete and contributes to increased EELV. ${ }^{23}$ Thus, resting EELV is determined by static and dynamic factors, and is a continuous dynamic variable.

Dynamic hyperinflation, defined as a variable increase in EELV above the relaxation volume, is a key mechanistic consequence of expiratory flow limitation in patients with COPD. ${ }^{18}$ The overall extent of dynamic hyperinflation during exercise is dictated by worsening expiratory flow limitation, increasing respiratory neural drive, and breathing pattern alterations (increased tidal volume and reduced expiratory time). ${ }^{11,18}$ Hyperinflation contributes to dyspnea, exercise intolerance (ultimately leading to reduced physical activity), and skeletal muscle deconditioning, which collectively contribute to poor quality of life in COPD. ${ }^{23}$ Although highly prevalent in advanced stages 
of COPD, dynamic hyperinflation also occurs in patients with mild-stage disease. ${ }^{9,23-25}$

The intensity of dyspnea during exercise is influenced by the extent of resting lung hyperinflation, and the magnitude of additional dynamic increases in air trapping during exercise. The greater the hyperinflation (resting and dynamic), the earlier the critical mechanical constraints on tidal volume expansion occur, marking the point in which dyspnea quickly escalates to intolerable levels. Measurement of IC provides indirect information about lung hyperinflation, which is relevant to the burden of dyspnea in the individual. Measurement of diffusing capacity of the lung for carbon monoxide and oxygen saturation during activity can provide insights into possible physiological mechanisms of breathlessness in the individual. ${ }^{26}$ Structural neurological changes are thought to be associated with chronic hypoxia. ${ }^{27}$ However, because changes in cerebral white and gray matter have also been observed in patients with non-hypoxemia COPD, further research is warranted to elucidate the exact mechanism that results in such structural brain changes. ${ }^{28}$ In addition, a study by Zhang et al found that patients with COPD had reduced gray matter volume in a number of brain regions (primarily the limbic/paralimbic regions and frontal cortices) compared with healthy volunteers. ${ }^{29}$ These observations are comparable to those seen in patients with obstructive sleep apnea syndrome versus healthy controls, and in structural brain modifications associated with highaltitude acclimatization. ${ }^{29,30}$

In addition to the changes observed following hypoxia and reduced oxygen supply, neuronal changes have also been associated with disease-specific fears. A study examining the relationship between disease duration, fear of dyspnea and physical activity, and structural brain changes found significantly greater decreases in gray matter volume in regions of the brain associated with processing dyspnea, fear, and antinociception when compared with healthy individuals. ${ }^{31}$ These changes were partially associated with longer disease duration and greater diseasespecific fears, which may contribute to poor outcomes in patients with COPD. ${ }^{31}$

\section{Psychological burden of dyspnea}

For many patients with COPD, anticipation of dyspnea is associated with increased physiological fear responses, activating fear-related areas of the brain. The involvement of emotion-related areas such as the insula, anterior cingulate cortex, and amygdala during dyspnea anticipation most likely reflects anticipatory fear in patients, leading to activity avoidance, and further increases in breathlessness. $^{32}$ The fear of dyspnea occurring can result in a patient experiencing more severe dyspnea during exercise. During a study investigating the effects of baseline anxiety and dyspnea-related fear on perceived dyspnea, higher dyspnea-related fear was associated with higher levels of dyspnea during ergometer exercise, and dyspnea-related fear was found to be a mediator of anxiety and exercise-related dyspnea. ${ }^{33}$

Biopsychological factors may, therefore, exacerbate the perception of dyspnea, increase symptom severity, and reduce quality of life. As well as acknowledging the influence of depression and anxiety on the prognosis of COPD, it is important to note that this association is bidirectional: a COPD diagnosis also increases the risk of developing depression. ${ }^{34}$ Furthermore, the increased respiratory rate seen in patients with anxiety may increase gas trapping, resulting in increased dyspnea. ${ }^{35}$ A better understanding of the interactions between biopsychological factors and dyspnea perception will enhance the development of symptomatic individualized treatments. ${ }^{36}$

Avoidance of physical activity to reduce dyspnea may begin even before COPD diagnosis. This can lead to a cycle of worsening symptoms, deconditioning, and disease progression, resulting in further limitations on physical activity. Patients should, therefore, be informed of the benefits of physical activity, and exercise training should be initiated to interrupt the cycle of decline that can lead to inactivity and worsen disease progression., 9,37-39

Dyspnea-related verbal cues can also stimulate the emotional circuitry of the brain in the absence of physical activity. Activation in the medial prefrontal cortex and anterior cingulate cortex independently correlated with the visual analog scale response to dyspnea word cues, as well as with patient responses to questionnaires on depression, fatigue, and dyspnea awareness. ${ }^{40}$

\section{Assessment of dyspnea in COPD}

Despite its prevalence, there is no universally agreed-upon measure of dyspnea. However, owing to its subjective nature, several scales have been developed for use in both research and clinical settings. ${ }^{41}$ When assessing the feasibility of a dyspnea measure intended for use in clinical (rather than research) settings, considerations such as time constraints should be accounted for. ${ }^{41}$ Therefore, clinicians may ask patients simple questions to assess the severity of dyspnea, such as what daily activities make 
them breathless, whether they avoid any activities, how frequently they use their rescue inhaler over a 24-hour period, or how their dyspnea symptoms vary throughout the day. ${ }^{42}$

In the absence of a universally endorsed dyspnea measure, physiological markers that are linked to dyspnea in COPD (including IC, measures of lung hyperinflation, diffusing capacity, and oxygen saturation) may be used as part of dyspnea assessment to measure or predict symptom burden and to identify reversible factors (eg, bronchodilators to reduce lung hyperinflammation; supplemental oxygen in select patients with activity-related arterial oxygen desaturation). ${ }^{43}$ For example, resting IC can be used to assess air trapping in COPD; decreases in IC are more closely related to dyspnea than forced expiratory volume in 1 $\mathrm{s}\left(\mathrm{FEV}_{1}\right)$ and forced vital capacity. ${ }^{21,22}$ As the relationship between low IC, chronic dyspnea, and reduced exercise capacity becomes clearer, it is evident that IC warrants further attention as a marker for physiological impairment in COPD in clinical and research settings alike. ${ }^{44}$

As $\mathrm{FEV}_{1}$ can be a less effective predictor of dyspnea than other measures, several validated questionnaires have been developed to facilitate a more comprehensive assessment of symptoms of breathlessness (Table 1). These include the modified MRC (mMRC) scale, the COPD Assessment Test (CAT), and the COPD Control Questionnaire, which are all recommended by the Global Initiative for Chronic Obstructive Lung Disease (GOLD), ${ }^{26}$ as well as the Chronic Respiratory Disease Questionnaire, Baseline Dyspnea Index, and the Transition Dyspnea Index. ${ }^{45-47}$ The 50-item St George's Respiratory Questionnaire (SGRQ), which contains a "symptoms" component that captures frequency of dyspnea in patients with COPD or asthma, is used as a research tool rather than in routine practice. ${ }^{26}$ Each assessment tool is associated with its own distinct advantages and limitations, and the most appropriate measure in a given scenario will depend on the patient, the clinical need, and the clinical setting.

As COPD-related anxiety and fear are prevalent comorbid complications that contribute significantly to COPD-specific disability, questionnaires have been designed to assess how this impacts patients' lives. The COPD Anxiety Questionnaire was designed for the assessment of fears, including fears of dyspnea, physical activity, and disease progression. ${ }^{48}$ In addition, the Anxiety Inventory for Respiratory disease (AIR) questionnaire assesses anxiety in patients experiencing dyspnea. By simplifying the assessment of anxiety in patients with COPD, the AIR questionnaire could be used in a clinical setting to evaluate the effectiveness of interventions to reduce anxiety. ${ }^{49}$

\section{Relieving dyspnea in COPD Pharmacologic interventions}

Pharmacologic treatments that target the sensory-perceptual and symptom impact domains of dyspnea are well documented (Figure 2). ${ }^{10}$ Bronchodilators, which reduce lung hyperinflation and respiratory muscle workload, are the mainstay of therapy for all patients with COPD, resulting in improvements in neuromechanical coupling of the respiratory system and, consequently, reductions in dyspnea. ${ }^{23}$ For patients with less symptom burden and a lower risk of exacerbation (GOLD category A [CAT score $<10$; mMRC dyspnea scale score $0-1]$ ), a short- or long-acting bronchodilator used as needed is recommended to relieve breathlessness. In more symptomatic patients (GOLD category B or D [CAT score $\geq 10$; mMRC $\geq 2]$ ) and/or those with less symptom burden at increased risk of exacerbation (GOLD category C [CAT score $<10$; mMRC 0-1]), long-acting bronchodilators are recommended as monotherapy or in combination. ${ }^{26}$

Dual bronchodilation with long-acting $\beta$-agonist/muscarinic receptor antagonist combinations, (eg, glycopyrrolate/indacaterol, umeclidinium/vilanterol, tiotropium/olodaterol, and glycopyrrolate/formoterol) can result in greater improvements in dyspnea, as assessed using Transition Dyspnea Index focal scores or SGRQ scores, compared with placebo and/or monocomponents. ${ }^{50-53}$ However, because no measure of dyspnea has been universally accepted by regulatory authorities, such as the US Food and Drug Administration, the majority of these bronchodilators are not indicated to reduce dyspnea. In addition, the exact minimal clinically important difference has not been determined for all measurements of dyspnea and cutoffs may be arbitrary for some measures.

Other agents such as opioids can reduce breathing discomfort by decreasing neural respiratory drive, altering central perception, and/or decreasing anxiety. ${ }^{16}$ A systematic review assessing the use of opioids in dyspnea management (in which 11 of the studies reviewed were focused specifically on patients with COPD) demonstrated a beneficial effect of both oral and parenteral opioids on the treatment of dyspnea $(P<0.001))^{54}$ However, the magnitude of effect was small and opiates did not improve exercise performance. ${ }^{54}$ Opioids are generally used in patients with end-stage disease only. ${ }^{10}$ 
Table I Assessment tools for dyspnea

\begin{tabular}{|c|c|c|}
\hline Questionnaire & Overview & Practice considerations \\
\hline $\begin{array}{l}\text { Baseline Dyspnea } \\
\text { Index, Transition } \\
\text { Dyspnea Index }{ }^{45-} \\
47\end{array}$ & $\begin{array}{l}\text { Multidimensional scales designed to provide information on the individual } \\
\text { components of dyspnea: } \\
\text { - Functional impairment } \\
\text { - Magnitude of task } \\
\text { - Magnitude of effort needed to evoke dyspnea } \\
\text { - Baseline Dyspnea Index rates the severity of dyspnea at baseline, whereas } \\
\text { Transitional Dyspnea Index quantifies changes from baseline }\end{array}$ & $\begin{array}{l}\text { Most commonly used as a research tool in } \\
\text { clinical trials } \\
\text { Assesses the impact of an intervention } \\
\text { Can be interview-based or self- } \\
\text { administered }\end{array}$ \\
\hline $\begin{array}{l}\text { Chronic } \\
\text { Respiratory } \\
\text { Questionnaire }^{81}\end{array}$ & $\begin{array}{l}\text { 20-item measure } \\
\text { Four aspects are examined: dyspnea, fatigue, emotional function, and mastery }\end{array}$ & $\begin{array}{l}\text { Self-administered version available } \\
\text { Not a dyspnea-specific measure }\end{array}$ \\
\hline $\begin{array}{l}\text { Clinical COPD } \\
\text { Questionnaire }^{26,82}\end{array}$ & $\begin{array}{l}\text { 10-item measure divided into three domains: symptoms, functional, and } \\
\text { mental state } \\
\text { Questions focus on symptoms during the past week, including dyspnea symptoms } \\
\text { and their impact on physical, daily, and social activities }\end{array}$ & $\begin{array}{l}\text { Recommended by GOLD } \\
\text { Most commonly used as a research tool in } \\
\text { clinical trials } \\
\text { Correlates well with SGRQ } \\
\text { Not a dyspnea-specific measure }\end{array}$ \\
\hline $\begin{array}{l}\text { COPD } \\
\text { Assessment } \\
\text { Test }^{26,83}\end{array}$ & $\begin{array}{l}\text { Eight items, three relevant to dyspnea, to measure the impact of COPD on } \\
\text { well-being and day-to-day activities } \\
\text { Five-point Likert scale determines the level of breathlessness after walking up a hill } \\
\text { or one flight of stairs, and assesses the extent of activity limitation at home }\end{array}$ & $\begin{array}{l}\text { Recommended by GOLD to evaluate } \\
\text { symptoms, including dyspnea; scoring } \geq 10 \\
\text { indicates a high level of symptoms (equiva- } \\
\text { lent to SGRQ score } \geq 25 \text { ) } \\
\text { Not a dyspnea-specific measure }\end{array}$ \\
\hline Dyspnea- $12^{84,85}$ & $\begin{array}{l}\text { I2-item measure across physical (seven items) and affective (five items) } \\
\text { domains } \\
\text { Items are scored on a scale of } 0 \text { (none), I (mild), } 2 \text { (moderate), or } 3 \text { (severe) } \\
\text { Total scores range } 0-36, \text { with high scores indicating greater severity }\end{array}$ & $\begin{array}{l}\text { Self-administered } \\
\text { Asks patients to reflect on how they are } \\
\text { experiencing dyspnea in their daily lives, } \\
\text { rather than in response to a specific activity }\end{array}$ \\
\hline $\begin{array}{l}\text { mMRC breath- } \\
\text { lessness } \\
\text { scale }^{26,86,87}\end{array}$ & $\begin{array}{l}\text { Five statements that describe almost the entire range of respiratory disability } \\
\text { from "none" (grade } 0 \text { ) to "almost complete incapacity" (grade 4) } \\
\text { The MRC scale does not quantify breathlessness itself but enables a numeric } \\
\text { value to be placed on exercise capacity }\end{array}$ & $\begin{array}{l}\text { Recommended by GOLD to evaluate } \\
\text { symptoms, including dyspnea. Grade } \geq 2 \\
\text { signifies a high level of symptoms } \\
\text { Self-administered; patients choose a phrase } \\
\text { that best describes their condition } \\
\text { Widely used in clinical practice }\end{array}$ \\
\hline $\begin{array}{l}\text { Multidimensional } \\
\text { Dyspnea Profile }\end{array}$ & $\begin{array}{l}\text { II-item measure that assess dyspnea across a sensory domain and two } \\
\text { affective domains (unpleasantness and emotional response) } \\
\text { Designed to examine individual items that are thought to be aligned to } \\
\text { separate mechanisms }\end{array}$ & $\begin{array}{l}\text { Can be self-administered, with support of } \\
\mathrm{HCP} \text { or trial investigator }\end{array}$ \\
\hline $\mathrm{SGRQ}^{26}$ & $\begin{array}{l}\text { 50-item measure divided into two parts } \\
\text { Scores range from } 0 \text { to } 100 \text {, with higher scores indicating greater limitation; } \\
\text { a score of } \geq 25 \text { is used as a threshold for considering regular treatment of } \\
\text { symptoms }\end{array}$ & $\begin{array}{l}\text { Recommended by GOLD } \\
\text { Too complex for use in routine practice, } \\
\text { but often used in clinical studies } \\
\text { Not a dyspnea-specific measure }\end{array}$ \\
\hline UCSD SOBQ ${ }^{89}$ & $\begin{array}{l}\text { 24-item measure } \\
\text { Assesses self-reported shortness of breath while performing various daily } \\
\text { activities } \\
\text { If the activities listed are not typically performed by the patient, the patient is } \\
\text { asked to estimate the degree of shortness of breath that they would anticipate } \\
\text { when completing the specified task } \\
\text { Three additional items ask about limitations due to shortness of breath, fear of harm } \\
\text { from overexertion, and fear of shortness of breath }\end{array}$ & $\begin{array}{l}\text { Self-administered } \\
\text { Provides comprehensive assessment of } \\
\text { dyspnea, but its length may present a less } \\
\text { practical option than other measures } \\
\text { for day-to-day clinical use }\end{array}$ \\
\hline
\end{tabular}

Abbreviations: GOLD, global initiative for chronic obstructive lung disease; HCP, healthcare professional; mMRC, modified Medical Research Council; MRC, Medical Research Council; SGRQ, St George's respiratory questionnaire; UCSD SOBQ, University of California, San Diego shortness of breath questionnaire. 


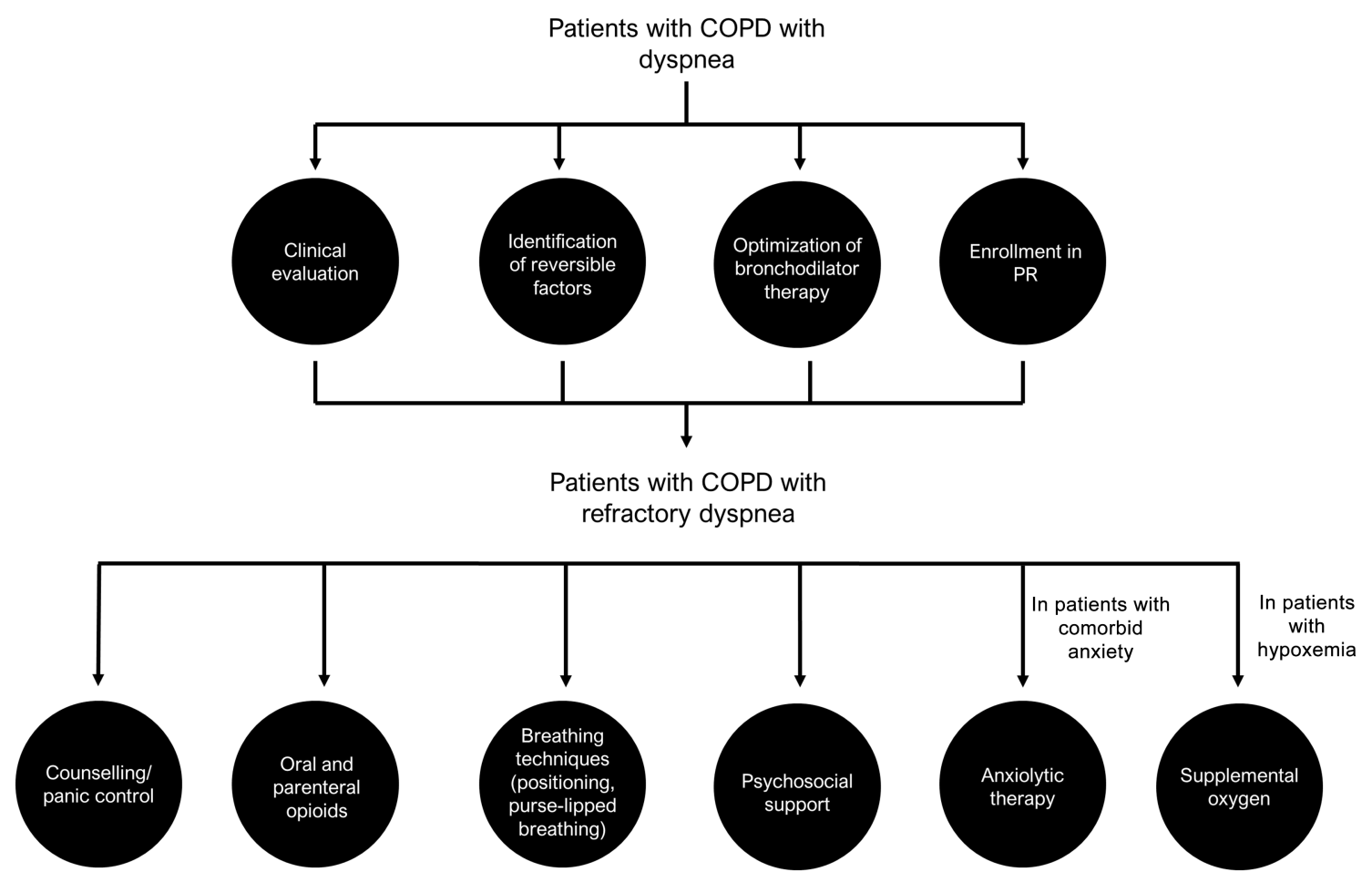

Figure 2 Paradigm to optimize control of dyspnea.

Abbreviation: PR, pulmonary rehabilitation.

Supplemental oxygen is recommended for patients with COPD with resting hypoxemia, as it can delay the onset of intolerable breathlessness during physical activity. ${ }^{10,26}$ However, the availability of supplemental oxygen is subject to insurance coverage policy. Although current guidelines do not recommend symptomatic therapy with supplemental oxygen for dyspnea in patients with COPD who do not meet the criteria for home oxygen therapy, selected non-hypoxemic patients with COPD may also benefit. The results from a metaanalysis of 431 mildly or non-hypoxemic patients with COPD indicated that oxygen could provide dyspnea relief in this population. However, data from a large, randomized trial are required to draw more definitive conclusions on the efficacy of this intervention. ${ }^{55}$

Evidence for the efficacy of pharmacologic treatments that target the affective component of dyspnea is somewhat limited, but opiates and anxiolytics are currently prescribed. Although opiates have demonstrated consistent effectiveness, there is conflicting evidence regarding the efficacy of anxiolytics in reducing dyspnea in patients with COPD. ${ }^{10,56}$

\section{Non-pharmacologic interventions}

Non-pharmacologic interventions, such as exercise training, inspiratory muscle training, pulmonary rehabilitation, and self-management programs, have been found to have a positive impact on the affective domain of dyspnea. ${ }^{57-60}$ Cognitive behavioral therapy has also shown to be effective in treating COPD-related anxiety and dyspnea in the short term, but further studies are required to establish whether such benefits are maintained over more extensive periods. ${ }^{61}$

The decline of physical activity associated with increasing dyspnea severity is the strongest predictor of mortality in patients with COPD. ${ }^{62}$ Monitoring physical activity and initiating exercise programs may help to reduce mortality rates and estimation of physical activity levels could be a useful tool in the management of COPD. In a crosssectional study, physical activity was found to differ according to $\mathrm{mMRC}$ grade, with a score of $\geq 2$ predicting a low physical activity level. ${ }^{63}$ Assessment of breathlessness by the mMRC questionnaire would be useful to stratify the risks of reduced physical activity in COPD. ${ }^{63}$

The importance of maintaining physical activity levels as much as possible is also reflected in COPD guidelines. GOLD 2019 notes the importance of pulmonary rehabilitation as part of an integrated approach to COPD management, offering considerable benefits to patients, such as improved exercise tolerance, better health status, and decreased dyspnea. ${ }^{26}$ The American Thoracic Society/European Respiratory Society statement describes pulmonary rehabilitation and pharmacotherapy as complementary approaches to COPD care with 
synergistic effects; pulmonary rehabilitation can result in reduced dyspnea, increased exercise capacity, improved quality of life, and lower the use of healthcare resources. ${ }^{64}$

Despite guideline recommendations, exercise intolerance caused by dyspnea is often observed in patients with COPD. However, scientific literature demonstrates the value of physical activity in improving patient outcomes. A populationbased cohort study of 2386 patients with COPD found that patients who performed some level of physical activity had a lower risk of hospital admissions and mortality than those who did not. ${ }^{65}$ Physical activity may also improve long-term outcomes and health-related quality of life, and reduces the risk of developing comorbidities. ${ }^{66}$ To increase levels of physical activity, behavioral change interventions are important; although bronchodilation and exercise training were shown to improve exercise tolerance and activity-related dyspnea in patients with COPD, a recent study found that enrollment in a behavioral modification program was required to improve levels of physical activity in study participants. ${ }^{67}$ Further investigations are needed to assess the use of physical activity in targeting the affective component of dyspnea.

Pulmonary rehabilitation has been observed to have a positive impact on reducing dyspnea in COPD. ${ }^{68}$ In a study of 48 patients randomized to either 8 weeks of pulmonary rehabilitation or their usual care, the sensory-perceptual, affective, and impact domains of dyspnea were assessed using scales including the Baseline Dyspnea Index, Transition Dyspnea Index, and MRC dyspnea scale. Although physiological training effects were not achieved, significant improvements were found in the affective and impact domains of dyspnea. ${ }^{58}$ This has been corroborated by a recent study, which demonstrated that pulmonary rehabilitation in COPD consistently altered brain activity in stimulus valuation networks measured by functional magnetic resonance imaging. ${ }^{69}$

Another technique that can help alleviate dyspnea is pursedlip breathing. In a randomized, crossover study, 40 patients with stable COPD aged 40-75 years with an $\mathrm{FEV}_{1}<60 \%$ performed pursed-lip and control breathing during constant work-rate exercise. ${ }^{70}$ In patients with low peak expiratory flow, pursedlip breathing reduced dynamic hyperinflation, as estimated using IC maneuvers at rest and during exercise, and improved exercise tolerance. However, it is important to note that these findings may not be transferable to real-world settings. ${ }^{70}$

Non-pharmacologic interventions are also a key element of the palliative management of dyspnea, in which symptoms are typically most problematic. Self-management interventions enable patients to actively participate in their care, which can help them to achieve better outcomes. ${ }^{71}$ Holistic services that encompass multidisciplinary team-supported strategies to help patients engage in self-management, in addition to providing educational and psychological support, have been shown to reduce distress due to breathlessness, and may improve psychological outcomes of anxiety and depression. ${ }^{72}$ Integration of such services would be a valuable addition to existing healthcare systems.

\section{Challenges, unmet needs, and future directions in the management of dyspnea in COPD}

There are various challenges in the management of dyspnea (Table 2). The subjective nature of dyspnea is reliant on patients' self-reporting symptoms. However, many patients self-limit physical activities, and therefore, underreport the severity of their dyspnea, making assessment difficult. ${ }^{73,74}$ Inaccurate assessment of dyspnea severity is particularly problematic in end-stage COPD when patients are most affected by dyspnea, but are less able to report their symptoms, ${ }^{75}$ and dyspnea is often assessed subjectively with observational methods only. ${ }^{76}$

Reduced physical activity is thought to have a behavioral component, in which patients choose to reduce activity. ${ }^{77}$ Self-limiting activities to reduce dyspnea can give the impression that the patient is less symptomatic than they actually are, but it is important that patients understand that activity avoidance can exacerbate dyspnea. Clinicians should discuss self-limiting behaviors with patients and educate them on the benefits of exercise through interventions such as self-management education and pulmonary rehabilitation. This could lead to improved health-related quality of life and management of dyspnea, ${ }^{78}$ and reduced healthcare utilization. $^{79}$ To maximize its value, self-management education should adopt a multifaceted approach that improves patient understanding of COPD and incorporates strategies to implement behavioral change. ${ }^{80}$

When looking to the future of COPD management, patients must be encouraged to increase their physical activity levels; a wealth of literature demonstrates that maintaining physical activity is a crucial component in effective management strategies and could lead to improved longterm outcomes. Self-management education, pulmonary rehabilitation in the form of skills training (eg, pursed-lip breathing while climbing stairs), encouraging use of patient diaries to monitor improvement, and individualized exercise programs can help create realistic and measurable goals for the patient. In order to support patients in achieving higher 
Table 2 Unmet needs in the management of dyspnea in COPD

\begin{tabular}{|l|l|}
\hline Unmet need & Current situation \\
\hline Measurement of dyspnea with validated tools & $\begin{array}{l}\text { Reliance on patients' self-reporting symptoms } \\
\text { Lack of a validated patient-reported outcome measure }\end{array}$ \\
\hline $\begin{array}{l}\text { Blood markers for assessment and treatment of } \\
\text { dyspnea }\end{array}$ & $\begin{array}{l}\text { Although some physiological markers (lung volume, lung hyperinflation measures, dif- } \\
\text { fusion capacity, and oxygen saturation) have been identified, there are no blood markers } \\
\text { for dyspnea }\end{array}$ \\
\hline Consensus on dyspnea assessment & No universally agreed upon measure of dyspnea \\
\hline $\begin{array}{l}\text { Further studies on the underlying mechanisms of } \\
\text { dyspnea }\end{array}$ & Understanding of neurophysiological mechanisms of dyspnea is incomplete \\
\hline $\begin{array}{l}\text { Multicenter, prospective, randomized controlled studies } \\
\text { of interventions for dyspnea }\end{array}$ & $\begin{array}{l}\text { Lack of agreed-upon, standardized measure of dyspnea } \\
\text { Lack of evidence base for existing and new dyspnea-relieving therapies }\end{array}$ \\
\hline $\begin{array}{l}\text { Further studies of the efficacy of self-management stra- } \\
\text { tegies and active palliation approaches }\end{array}$ & $\begin{array}{l}\text { Lack of consistent guidance on the best ways to address self-limiting behaviors and } \\
\text { optimize end-of-life care }\end{array}$ \\
\hline
\end{tabular}

and sustained levels of physical activity, behavioral and cognitive modification programs that can alter the affective component of dyspnea should be developed and validated.

Comprehensive management of dyspnea using an approach tailored to the patient's symptoms and exacerbation risk has a significant positive effect on treatment outcomes. ${ }^{26}$ The 2019 GOLD strategy recommends considering dual bronchodilation, for example, in those with severe symptoms or at high risk of exacerbations, whereas monotherapy with a bronchodilator would be the starting point for less symptomatic patients. $^{26}$

In addition to clinical recommendations, it is important to consider research needs and subjects that warrant further investigation. Mechanistic neurophysiological studies are required to better understand the complex dyspnea "matrix" and to determine how this can be manipulated for the patient's benefit by targeted, individualized interventions. Identification of validated tools for COPD assessment should be prioritized. These should be reproducible and multidimensional, providing a suitable means to assess COPD symptoms and possible factors that contribute to dyspnea, and that would be adoptable by regulators and healthcare professionals alike. Large prospective randomized multicenter controlled studies are needed to formulate evidence-based guidelines for existing dyspnea-relieving therapies, such as oxygen supplementation, opiates, anxiolytics, and treatment combinations. New studies are required to refine and evaluate efficacy of collaborative self-management planning, active palliation approaches for those with advanced COPD, and optimization of end-of-life care.

\section{Conclusion}

The physical and psychological consequences of dyspnea in patients with COPD are significant. Our understanding of the complex mechanisms underlying dyspnea, in terms of pathophysiology, neurobiology, and effect on physical functioning, has advanced considerably in recent years. These new insights into the nature and source of this distressing symptom have informed an approach to treatment that incorporates both pharmacologic and non-pharmacologic interventions to target its physical and psychological consequences.

Although our understanding of the impact of dyspnea on patients with COPD has improved, significant unmet needs around its effective management persist. It is important to help patients with COPD overcome their fear of experiencing dyspnea during, or in anticipation of, physical activity. This requires continuous dialog and support from their healthcare providers who encourage regular physical activity and appropriate pharmacologic management of dyspnea.

\section{Acknowledgments}

Medical writing support, including assisting authors with the development of the outline and initial draft, and incorporation of comments, fact checking, and referencing, was provided by Hannah Burke, BSc, of Core (London, UK) and editorial support, including figure preparation, formatting, proofreading, and submission, was provided by Maryam Vahdat, PGDip, of Core (London, UK), which were funded by AstraZeneca LP (Wilmington, DE, USA), in accordance with Good Publication Practice (GPP3) guidelines (Battisti WP, Wager E, Baltzer L, Bridges D, Cairns A, Carswell CI, 
et al. Good Publication Practice for Communicating Company-Sponsored Medical Research: GPP3. Ann Intern Med. 2015;163:461-464. doi:10.7326/M15-0288).

\section{Disclosure}

NAH has received honoraria for serving on an advisory board or as a consultant for Genentech Inc., Roche, Sunovion Pharmaceuticals Inc., Novartis AG, AstraZeneca plc, and GlaxoSmithKline plc. His institution has received research grants on his behalf from Genentech, GlaxoSmithKline plc, Boehringer Ingelheim $\mathrm{GmbH}$, Mylan., Sunovion Pharmaceuticals Inc., and AstraZeneca plc. DEO serves as a consultant to AstraZeneca plc, Boehringer Ingelheim GmbH, GlaxoSmithKline plc, and Novartis AG, and serves on the advisory boards of AstraZeneca plc, and Boehringer Ingelheim GmbH. His institution has received grant support from Boehringer Ingelheim $\mathrm{GmbH}$ and Novartis AG. DEO co-edited a book titled Dyspnea: Mechanisms, Measurement, and Management, 3rd edition, published by CRC Press, Taylor and Francis Group, and may receive royalties from sales of this book. The authors report no other conflicts of interest in this work.

\section{References}

1. Parshall MB, Schwartzstein RM, Adams L, et al. An official American Thoracic Society statement: update on the mechanisms, assessment, and management of dyspnea. Am $J$ Respir Crit Care Med. 2012;185:435-452. doi:10.1164/rccm.201111-2042ST

2. Roche N. Activity limitation: a major consequence of dyspnoea in COPD. Eur Respir Rev. 2009;18:54-57. doi:10.1183/ 09059180.00001309

3. Mullerova H, Lu C, Li H, Tabberer M. Prevalence and burden of breathlessness in patients with chronic obstructive pulmonary disease managed in primary care. PLoS One. 2014;9:e85540. doi:10.1371/ journal.pone.0085540

4. Pumar MI, Gray CR, Walsh JR, Yang IA, Rolls TA, Ward DL. Anxiety and depression - important psychological comorbidities of COPD. $J$ Thorac Dis. 2014;6:1615-1631. doi:10.3978/j.issn.20721439.2014.09.28

5. O'Donnell DE, Laveneziana P. Dyspnea and activity limitation in COPD: mechanical factors. COPD. 2007;4:225-236. doi:10.1080/ 15412550701480455

6. Faisal A, Alghamdi BJ, Ciavaglia CE, et al. Common mechanisms of dyspnea in chronic interstitial and obstructive lung disorders. $\mathrm{Am}$ $J$ Respir Crit Care Med. 2016;193:299-309. doi:10.1164/ rccm.201504-08410C

7. Guenette JA, Chin RC, Cheng S, et al. Mechanisms of exercise intolerance in global initiative for chronic obstructive lung disease grade 1 COPD. Eur Respir J. 2014;44:1177-1187. doi:10.1183/09031936.00034714

8. O'Donnell DE, Ora J, Webb KA, Laveneziana P, Jensen D. Mechanisms of activity-related dyspnea in pulmonary diseases. Respir Physiol Neurobiol. 2009;167:116-132. doi:10.1016/j.resp.2009.01.010
9. Elbehairy AF, Guenette JA, Faisal A, et al. Mechanisms of exertional dyspnoea in symptomatic smokers without COPD. Eur Respir J. 2016;48:694-705. doi:10.1183/13993003.00077-2016

10. O'Donnell DE, Webb KA, Harle I, Neder JA. Pharmacological management of breathlessness in COPD: recent advances and hopes for the future. Expert Rev Respir Med. 2016;10:823-834. doi:10.1080/ 17476348.2016.1182867

11. O'Donnell DE. Hyperinflation, dyspnea, and exercise intolerance in chronic obstructive pulmonary disease. Proc Am Thorac Soc. 2006;3:180-184. doi:10.1513/pats.200508-093DO

12. O'Donnell DE, Banzett RB, Carrieri-Kohlman V, Al E. Pathophysiology of dyspnea in chronic obstructive pulmonary disease: a roundtable. Proc Am Thorac Soc. 2007;4:145-168. doi:10.1513/pats.200611-159CC

13. Raghavan N, Webb K, Amornputtisathaporn N, O'Donnell DE. Recent advances in pharmacotherapy for dyspnea in COPD. Curr Opin Pharmacol. 2011;11:204-210. doi:10.1016/j.coph.2011.03.002

14. O'Donnell DE. Activity-related dyspnoea in chronic pulmonary diseases: new mechanistic insights. Tanaffos. 2017;16:S5-S6.

15. O'Donnell DE, Elbehairy AF, Berton DC, Domnik NJ, Neder JA. Advances in the evaluation of respiratory pathophysiology during exercise in chronic lung diseases. Front Physiol. 2017;8:82.

16. Mahler DA, O'Donnell DE. Recent advances in dyspnea. Chest. 2015;147:232-241. doi:10.1378/chest.14-0800

17. Antoniu SA. Descriptors of dyspnea in obstructive lung diseases. Multidiscip Respir Med. 2010;5:216-219. doi:10.1186/2049-69585-3-216

18. O'Donnell DE, Webb KA, Neder JA. Lung hyperinflation in COPD: applying physiology to clinical practice. COPD Res Pract. 2015;1:4. doi:10.1186/s40749-015-0008-8

19. Guenette JA, Webb KA, O'Donnell DE. Does dynamic hyperinflation contribute to dyspnoea during exercise in patients with COPD? Eur Respir J. 2012;40:322-329. doi:10.1183/09031936.00157711

20. Stickland MK, Fuhr DP, Edgell H, et al. Chemosensitivity, cardiovascular risk, and the ventilatory response to exercise in COPD. PLoS One. 2016;11:e0158341. doi:10.1371/journal.pone.0158341

21. Ferguson GT. Why does the lung hyperinflate? Proc Am Thorac Soc. 2006;3:176-179. doi:10.1513/pats.200508-094DO

22. Nishimura K, Yasui M, Nishimura T, Oga T. Airflow limitation or static hyperinflation: which is more closely related to dyspnea with activities of daily living in patients with COPD? Respir Res. 2011;12:135. doi:10.1186/1465-9921-12-122

23. Gagnon P, Guenette JA, Langer D, et al. Pathogenesis of hyperinflation in chronic obstructive pulmonary disease. Int J Chron Obstruct Pulmon Dis. 2014;9:187-201. doi:10.2147/COPD.S38934

24. Ofir D, Laveneziana P, Webb KA, Lam YM, O'Donnell DE. Mechanisms of dyspnea during cycle exercise in symptomatic patients with GOLD stage I chronic obstructive pulmonary disease. Am J Respir Crit Care Med. 2008;177:622-629. doi:10.1164/ rccm.200707-1064OC

25. Chin RC, Guenette JA, Cheng S, et al. Does the respiratory system limit exercise in mild chronic obstructive pulmonary disease? Am J Respir Crit Care Med. 2013;187:1315-1323. doi:10.1164/ rccm.201211-1970OC

26. GOLD. Global initiative for chronic obstructive lung disease. Available from: https://goldcopd.org/wp-content/uploads/2018/11/GOLD-2019POCKET-GUIDE-FINAL_WMS.pdf. Accessed March 122019.

27. Ozge C, Ozge A, Unal O. Cognitive and functional deterioration in patients with severe COPD. Behav Neurol. 2006;17:121-130.

28. Dodd JW, Chung AW, van Den Broek MD, Barrick TR, Charlton RA, Jones PW. Brain structure and function in chronic obstructive pulmonary disease: a multimodal cranial magnetic resonance imaging study. Am J Respir Crit Care Med. 2012;186:240-245. doi:10.1164/ rccm.201202-0355OC 
29. Zhang H, Wang X, Lin J, et al. Reduced regional gray matter volume in patients with chronic obstructive pulmonary disease: a voxel-based morphometry study. AJNR Am J Neuroradiol. 2013;34:334-339. doi:10.3174/ajnr.A3235

30. Zhang J, Yan X, Shi J, Gong Q, Weng X, Liu Y. Structural modifications of the brain in acclimatization to high-altitude. PLoS One. 2010;5:e11449. doi:10.1371/journal.pone.0011449

31. Esser RW, Stoeckel MC, Kirsten A, et al. Structural brain changes in patients with COPD. Chest. 2016;149:426-434. doi:10.1378/ chest.15-0027

32. Stoeckel MC, Esser RW, Gamer M, Buchel C, von Leupoldt A. Brain responses during the anticipation of dyspnea. Neural Plast. 2016;2016:6434987. doi:10.1155/2016/5260671

33. Janssens T, De Peuter S, Stans L, et al. Dyspnea perception in COPD: association between anxiety, dyspnea-related fear, and dyspnea in a pulmonary rehabilitation program. Chest. 2011;140:618-625. doi:10.1378/chest.10-3257

34. Atlantis E, Fahey P, Cochrane B, Smith S. Bidirectional associations between clinically relevant depression or anxiety and COPD: a systematic review and meta-analysis. Chest. 2013;144:766-777. doi:10.1378/chest.12-1911

35. Cooper CB. The connection between chronic obstructive pulmonary disease symptoms and hyperinflation and its impact on exercise and function. $\mathrm{Am} \quad \mathrm{J}$ Med. 2006;119:21-31. doi:10.1016/j. amjmed.2006.08.004

36. Hayen A, Herigstad M, Pattinson KT. Understanding dyspnea as a complex individual experience. Maturitas. 2013;76:45-50. doi:10.1016/j.maturitas.2013.06.005

37. O'Donnell DE, Gebke KB. Activity restriction in mild COPD: a challenging clinical problem. Int J Chron Obstruct Pulmon Dis. 2014;9:577-588. doi:10.2147/COPD.S62766

38. Troosters T, Sciurba F, Battaglia S, et al. Physical inactivity in patients with COPD, a controlled multi-center pilot-study. Respir Med. 2010;104:1005-1011. doi:10.1016/j.rmed.2010.01.012

39. Vozoris NT, O'Donnell DE. Smoking, activity level and exercise test outcomes in a young population sample without cardiopulmonary disease. J Sports Med Phys Fitness. 2015;55:787-796.

40. Herigstad M, Hayen A, Evans E, et al. Dyspnea-related cues engage the prefrontal cortex: evidence from functional brain imaging in COPD. Chest. 2015;148:953-961. doi:10.1378/chest.15-0416

41. Bausewein C, Farquhar M, Booth S, Gysels M, Higginson IJ. Measurement of breathlessness in advanced disease: a systematic review. Respir Med. 2007;101:399-410. doi:10.1016/j. rmed.2006.07.003

42. Belfer MH, Reardon JZ. Improving exercise tolerance and quality of life in patients with chronic obstructive pulmonary disease. $\mathrm{J} \mathrm{Am}$ Osteopath Assoc. 2009;109:268-278.

43. Anzueto A, Miravitlles M. Pathophysiology of dyspnea in COPD. Postgrad Med. 2017;129:366-374. doi:10.1080/00325481.2017.1301190

44. O'Donnell DE, Elbehairy AF, Webb KA, Neder JA. The link between reduced inspiratory capacity and exercise intolerance in chronic obstructive pulmonary disease. Ann Am Thorac Soc. 2017;14:S30 S39. doi:10.1513/AnnalsATS.201610-834FR

45. Jones P, Lareau S, Mahler DA. Measuring the effects of COPD on the patient. Respir Med. 2005;99 Suppl B:S11-S18. doi:10.1016/j. rmed.2005.09.011

46. Mahler DA, Ward J, Fierro-Carrion G, et al. Development of self-administered versions of modified baseline and transition dyspnea indexes in COPD. COPD. 2004;1:165-172.

47. Mahler DA, Waterman LA, Ward J, McCusker C, ZuWallack R, Baird JC. Validity and responsiveness of the self-administered computerized versions of the baseline and transition dyspnea indexes. Chest. 2007;132:1283-1290. doi:10.1378/chest.07-0703
48. Keil DC, Stenzel NM, Kuhl K, et al. The impact of chronic obstructive pulmonary disease-related fears on disease-specific disability. Chron Respir Dis. 2014;11:31-40. doi:10.1177/1479972313516881

49. Willgoss TG, Goldbart J, Fatoye F, Yohannes AM. The development and validation of the anxiety inventory for respiratory disease. Chest. 2013;144:1587-1596. doi:10.1378/chest.13-0168

50. Bateman ED, Ferguson GT, Barnes N, et al. Dual bronchodilation with QVA149 versus single bronchodilator therapy: the SHINE study. Eur Respir J. 2013;42:1484-1494. doi:10.1183/09031936.00200212

51. Donohue JF, Maleki-Yazdi MR, Kilbride S, Mehta R, Kalberg C, Church A. Efficacy and safety of once-daily umeclidinium/vilanterol 62.5/25 mcg in COPD. Respir Med. 2013;107:1538-1546. doi:10.1016/j.rmed.2013.06.001

52. Buhl R, Maltais F, Abrahams R, et al. Tiotropium and olodaterol fixed-dose combination versus mono-components in COPD (GOLD 2-4). Eur Respir J. 2015;45:969-979. doi:10.1183/09031936.00136014

53. Martinez FJ, Rabe KF, Ferguson GT, et al. Efficacy and safety of glycopyrrolate/formoterol metered dose inhaler formulated using Co-Suspension Delivery Technology in patients with COPD. Chest. 2017;151:340-357. doi:10.1016/j.chest.2016.11.028

54. Jennings AL, Davies AN, Higgins JP, Gibbs JS, Broadley KE. A systematic review of the use of opioids in the management of dyspnoea. Thorax. 2002;57:939-944.

55. Uronis H, McCrory DC, Samsa G, Currow D, Abernethy A. Symptomatic oxygen for non-hypoxaemic chronic obstructive pulmonary disease. Cochrane Database Syst Rev. 2011;15:CD006429.

56. Nishino T. Dyspnoea: underlying mechanisms and treatment. $\mathrm{Br}$ $J$ Anaesth. 2011;106:463-474. doi:10.1093/bja/aer040

57. Donesky D, Nguyen HQ, Paul SM, Carrieri-Kohlman V. The affective dimension of dyspnea improves in a dyspnea self-management program with exercise training. J Pain Symptom Manage. 2014;47:757-771. doi:10.1016/j.jpainsymman.2013.05.019

58. Wadell K, Webb KA, Preston ME, et al. Impact of pulmonary rehabilitation on the major dimensions of dyspnea in COPD. COPD. 2013;10:425-435. doi:10.3109/15412555.2012.758696

59. Langer D, Ciavaglia CE, Faisal A, et al. Inspiratory muscle training reduces diaphragm activation and dyspnea during exercise in COPD. J Appl Physiol (1985). 2018;125:381-392. doi:10.1152/ japplphysiol.01078.2017

60. Gosselink R, De Vos J, van den Heuvel SP, Segers J, Decramer M, Kwakkel G. Impact of inspiratory muscle training in patients with COPD: what is the evidence? Eur Respir J. 2011;37:416-425. doi:10.1183/09031936.00031810

61. Yohannes AM, Junkes-Cunha M, Smith J, Vestbo J. Management of dyspnea and anxiety in chronic obstructive pulmonary disease: a critical review. J Am Med Dir Assoc. 2017;18(1096):e1091-e1096 e1017. doi:10.1016/j.jamda.2017.09.007

62. Waschki B, Kirsten A, Holz O, et al. Physical activity is the strongest predictor of all-cause mortality in patients with COPD: a prospective cohort study. Chest. 2011;140:331-342. doi:10.1378/chest.10-2521

63. Hayata A, Minakata Y, Matsunaga K, Nakanishi M, Yamamoto N. Differences in physical activity according to $\mathrm{mMRC}$ grade in patients with COPD. Int J Chron Obstruct Pulmon Dis. 2016;11:2203-2208. doi:10.2147/COPD.S109694

64. Celli BR, Decramer M, Wedzicha JA, et al. An Official American Thoracic Society/European Respiratory Society Statement: research questions in chronic obstructive pulmonary disease. Am J Respir Crit Care Med. 2015;191:e4-e27. doi:10.1164/rccm.201501-0044ST

65. Garcia-Aymerich J, Lange P, Benet M, Schnohr P, Anto JM. Regular physical activity reduces hospital admission and mortality in chronic obstructive pulmonary disease: a population based cohort study. Thorax. 2006;61:772-778. doi:10.1136/thx.2006.060145 
66. Troosters T, van der Molen T, Polkey M, et al. Improving physical activity in COPD: towards a new paradigm. Respir Res. 2013;14:115. doi:10.1186/1465-9921-14-19

67. Troosters T, Maltais F, Leidy N, et al. Effect of bronchodilation and exercise training with behavior modification on exercise tolerance and downstream effects on symptoms and physical activity in COPD. Am J Respir Crit Care Med. 2018;198:1021-1032. doi:10.1164/ rccm.201706-12880C

68. McCarthy B, Casey D, Devane D, Murphy K, Murphy E, Lacasse Y. Pulmonary rehabilitation for chronic obstructive pulmonary disease. Cochrane Database Syst Rev. 2015;(2):CD003793.

69. Herigstad M, Faull OK, Hayen A, et al. Treating breathlessness via the brain: changes in brain activity over a course of pulmonary rehabilitation. Eur Respir J. 2017;50:1701029.

70. Cabral LF, D'Elia Tda C, Marins Dde S, Zin WA, Guimaraes FS. Pursed lip breathing improves exercise tolerance in COPD: a randomized crossover study. Eur $J$ Phys Rehabil Med. 2015;51:79-88.

71. Spathis A, Booth S, Moffat C, et al. The Breathing, Thinking, Functioning clinical model: a proposal to facilitate evidence-based breathlessness management in chronic respiratory disease. NPJ Prim Care Respir Med. 2017;27:27. doi:10.1038/s41533-017-0024-Z

72. Brighton LJ, Miller S, Farquhar M, et al. Holistic services for people with advanced disease and chronic breathlessness: a systematic review and meta-analysis. Thorax. 2018;74:270-281. doi:10.1136/ thoraxjnl-2018-211589

73. American Thoracic Society. Dyspnea: mechanisms, assessment, and management: a consensus statement. Am J Respir Crit Care Med. 1999;159:321-340. doi:10.1164/ajrccm.159.1.ats898

74. Ries AL. Impact of chronic obstructive pulmonary disease on quality of life: the role of dyspnea. Am J Med. 2006;119:12-20. doi:10.1016/ j.amjmed.2006.08.003

75. Jones I, Kirby A, Ormiston P, et al. The needs of patients dying of chronic obstructive pulmonary disease in the community. Fam Pract. 2004;21:310-313.

76. Webb M, Moody LE, Mason LA. Dyspnea assessment and management in hospice patients with pulmonary disorders. Am J Hosp Palliat Care. 2000;17:259-264. doi:10.1177/104990910001700412

77. Polkey MI, Rabe KF. Chicken or egg: physical activity in COPD revisited. Eur Respir J. 2009;33:227-229. doi:10.1183/09031936.00176808
78. Zwerink M, Brusse-Keizer M, van der Valk PD, et al. Self management for patients with chronic obstructive pulmonary disease. Cochrane Database Syst Rev. 2014;(3):CD002990.

79. Bourbeau J, Julien M, Maltais F, et al. Reduction of hospital utilization in patients with chronic obstructive pulmonary disease: a disease-specific self-management intervention. Arch Intern Med. 2003;163:585-591.

80. Bourbeau J, Nault D, Dang-Tan T. Self-management and behaviour modification in COPD. Patient Educ Couns. 2004;52:271-277. doi:10.1016/S0738-3991(03)00102-2

81. Guyatt GH, Berman LB, Townsend M, Pugsley SO, Chambers LW. A measure of quality of life for clinical trials in chronic lung disease. Thorax. 1987;42:773-778.

82. van der Molen T, Willemse BW, Schokker S, ten Hacken NH, Postma DS, Juniper EF. Development, validity and responsiveness of the clinical COPD questionnaire. Health Qual Life Outcomes. 2003;1:13. doi:10.1186/1477-7525-1-13

83. Karloh M, Fleig Mayer A, Maurici R, Pizzichini MM, Jones PW, Pizzichini E. The COPD Assessment Test: what do we know so far?: a systematic review and meta-analysis about clinical outcomes prediction and classification of patients into GOLD stages. Chest. 2016;149:413-425. doi:10.1378/chest.15-1752

84. Williams MT, John D, Frith P. Comparison of the dyspnoea-12 and multidimensional dyspnoea profile in people with COPD. Eur Respir J. 2017;49:1600773.

85. Yorke J, Swigris J, Russell AM, et al. Dyspnea-12 is a valid and reliable measure of breathlessness in patients with interstitial lung disease. Chest. 2011;139:159-164. doi:10.1378/chest.10-0693

86. Fletcher CM, Elmes PC, Fairbairn AS, Wood CH. The significance of respiratory symptoms and the diagnosis of chronic bronchitis in a working population. $\mathrm{Br}$ Med J. 1959;2:257-266.

87. Stenton C. The MRC breathlessness scale. Occup Med (Lond). 2008;58:226-227. doi:10.1093/occmed/kqm162

88. Banzett RB, O'Donnell CR, Guilfoyle TE, et al. Multidimensional dyspnea profile: an instrument for clinical and laboratory research. Eur Respir J. 2015;45:1681-1691. doi:10.1183/09031936.00038914

89. Eakin EG, Resnikoff PM, Prewitt LM, Ries AL, Kaplan RM. Validation of a new dyspnea measure: the UCSD shortness of breath questionnaire. University of California, San Diego. Chest. 1998;113:619-624.

\section{Publish your work in this journal}

The International Journal of COPD is an international, peer-reviewed journal of therapeutics and pharmacology focusing on concise rapid reporting of clinical studies and reviews in COPD. Special focus is given to the pathophysiological processes underlying the disease, intervention programs, patient focused education, and self management protocols. This journal is indexed on PubMed Central, MedLine and CAS. The manuscript management system is completely online and includes a very quick and fair peer-review system, which is all easy to use. Visit http://www.dovepress.com/testimonials.php to read real quotes from published authors. 